\title{
㲅 \\ Limitation of the spread and impact of infectious coryza through the use of a continuous disinfection programme
}

\section{R.R. BRAGG}

Department of Microbial, Biochemical and Food Biotechnology, University of the Free State, P.O. Box 339, Bloemfontein, 9300 South Africa. E-mail: BraggRR@sci.uovs.ac.za

\begin{abstract}
BRAGG, R.R. 2004. Limitation of the spread and impact of infectious coryza through the use of a continuous disinfection programme. Onderstepoort Journal of Veterinary Research, 71:1-8

The effect of a continuous disinfection programme, using the non-toxic disinfectant Virukill, in layers, on the spread and impact of infectious coryza, caused by Haemophilus paragallinarum was evaluated.

In this experiment, both unvaccinated layers and layers vaccinated against infectious coryza were used. Duplicate smaller groups of vaccinated and unvaccinated chickens were challenged with different serovars of both NAD-dependent as well as NAD-independent isolates of Haemophilus paragallinarum. One group of chickens challenged with each of the different bacterial serovars was treated with the continuous disinfection programme, while the other group remained as the untreated controls.

The clinical signs of infectious coryza were evaluated over a period of 20 days in each group. The egg production over this period was also evaluated.

It was found in all experimental challenges, that the severity of the symptoms was reduced in the birds receiving the continuous disinfection programme. The drop in egg production was also found to be less severe in the treated groups when compared to the untreated control groups. The duration of infection was found to be either unchanged, or shorter in the birds treated with the continuous disinfection programme. In none of the experimental challenges was the duration or expression of clinical signs of IC increased due to the continuous disinfection programme.
\end{abstract}

Keywords: Continuous disinfection, Haemophilus paragallinarum, infectious coryza, Virukill

\section{INTRODUCTION}

Infectious coryza (IC), caused by the bacterium Haemophilus paragallinarum, remains a serious problem to the poultry industries in many countries, despite the wide-spread use of commercial vaccines.

It has been demonstrated that there are four different serovars of NAD-dependent $H$. paragallinarum

Accepted for publication 24 June 2003-Editor currently in South Africa (Kume, Sawata, Nakase \& Matsumoto 1983; Blackall, Eaves \& Rogers 1990; Bragg, Coetzee \& Verschoor 1996). During an investigation of the incidence of the four serovars of NAD-dependent $H$. paragallinarum in South Africa, Bragg et al. (1996) discovered that there had been a significant change in the incidence of the different serovars over a thirty-year period. It was shown that the incidence of serogroup A isolates had all but disappeared in the 1990s, while the incidence of serovar C-3 had increases significantly during this period. This lead Bragg et al. (1996) to postu- 
late that these changes in the incidence of the different isolates was possibly a result of the use of vaccines in this country not containing the correct serovars for this country. As a result of these findings, Bragg et al. (1996) and Bragg, Greyling \& Verschoor (1997) postulated that there is a need for vaccines containing local isolates in countries where unique serovars of $H$. paragallinarum occur.

Bragg (2002b) further demonstrated that the serovar C-3 strain of NAD-dependent $H$. paragallinarum was highly virulent when compared to the other serogroups of NAD-dependent $H$. paragallinarum. The high virulence of serovar $\mathrm{C}-3$ isolates could also be a possible reason for the increase in incidence of this serovar in South Africa reported on by Bragg et al. (1996).

Further evidence of the failure of commercially available vaccines for the control of IC was obtained recently in Zimbabwe where a severe outbreak, which was caused by the serovar C-3 strain, was reported (Bragg 2002a).

The IC situation in South Africa was further complicated with the discovery of NAD-independent variants of $H$. paragallinarum in the early 1990 s when Horner, Bishop \& Haw (1992) reported on a bacterium that appeared to be $H$. paragallinarum, but did not require NAD for growth. They suggested that these isolates could not be $H$. paragallinarum because of the NAD independence. Mouahid, Bisgaard, Morley, Mutters \& Mannheim (1992), Bragg, Coetzee \& Verschoor (1993) and Bragg et al. (1997) suggested that these isolates were NAD-independent variants of $H$. paragallinarum based on DNA/ DNA hybridization (Mouahid et al. 1992) and reactions with monoclonal antibodies specific for $H$. paragallinarum (Bragg et al. 1993). Horner, Bishop, Jarvis \& Coetzee (1995) later conceded that their isolates were NAD-independent $H$. paragallinarum.

The main emphasis on the control of IC should remain on the establishment of the most suitable vaccine to combat all of the strains in a particular country. The development, testing and registration of a new vaccine, however, many take some time. There is thus a need for a simple method for the limitation of the effects of IC in the layers.

The disinfectant (Virukill, ICA international Chemicals, P.O. Box 2312 Stellenbosch, South Africa 7601 ) is a patented formulation of a quaternary ammonium compound, in which the efficacy of the active ingredient has been boosted without increasing the toxicity of the product. It consists of a mod- ification based on a $12 \%$ didecyl dimethyl ammonium chloride (DDAC) solution. This product has been shown to have a very low toxicity (data not shown) and a high efficacy against poultry viruses and bacteria (data not shown). Because of this low toxicity and high efficacy, the possibilities of using this product for continuous disinfection during poultry production was investigated. The continuous disinfection programme consists of disinfection of hard surfaces during cleanout, treatment of the drinking water and spraying of the birds during production. Bragg \& Plumstead (2003) demonstrated that the full continuous disinfection programme reduced mortalities in broilers under experimental conditions as well as under field conditions in the face of a Newcastle Disease virus challenge. This raised the question of the possibilities of using the full continual disinfection programme that was developed for broilers to control the impact of IC in layers.

In these experiments, the effects of treating chickens that have been experimentally infected with various serovars of both NAD-dependent and NADindependent $H$. paragallinarum, using the continuous disinfection program with DDAC was investigated. At the time of these experiments, this disinfectant was the only product available that was registered in South Africa (through Act 36 of 1947) for use in the drinking water of birds and to spray the birds with.

\section{METHODS AND MATERIALS}

\section{Chickens}

A total of 100 unvaccinated commercial layer chickens were obtained from a supplier of point-of-lay chickens. These chickens were obtained at 11 weeks of age before they were vaccinated against IC and originated from a site with no previous history of IC. The chickens were housed in layer facilities until they were used in the experiments.

A total of 100 vaccinated commercial point-of-lay chickens were obtained from the same flock from which the unvaccinated chickens were obtained. These chickens had remained on the commercial farm and were vaccinated with the Onderstepoort Biological products (OBP) IC vaccine at 12 weeks with a re-vaccination at 16 weeks. The OBP IC vaccine contains serogroup $A$ and $C$ strains as well as the Tongaat strain. These chickens remained on the farm until they were 18 weeks of age. After this time, they were moved to the same facilities as the 
unvaccinated groups. Both vaccinated and unvaccinated chickens remained in the facilities until they were 25 weeks of age and were producing eggs.

A total of 20 vaccinated and 20 unvaccinated chickens were removed and placed into layer cages in isolation facilities were they were further sub-divided into two groups of ten vaccinated and two groups of ten unvaccinated chickens. They were placed into cages in such a way that ten chickens were placed into the top five cages (two chickens per cage) and ten chickens were placed into the bottom row of cages. The vaccinated chickens were placed on one side of the battery of cages, while the unvaccinated chickens were placed onto the other side. The drinking water of the bottom row of cages was treated with 100 ppm DDAC daily.

Thereafter the birds were challenged with one of the four different serovars of NAD-dependent $H$. paragallinarum isolates or an NAD-independent isolate according to the methods below.

\section{Challenge and treatment methods}

The chickens were challenged according to the methods described by Bragg (2001b) without modification. Basically one chicken in the middle cage was selected and challenged with intra-sinus injection of $0.1 \mathrm{~m} \ell$ of the challenge bacterium. The remaining birds in the group were then infected via natural challenge routes. The clinical signs in the birds were recorded and scored for a 20-day period. The severity of the clinical signs was given a numerical value according to the methods described by Bragg (2002b) such that birds with no clinical signs receive a score of 0 , birds with mild clinical signs in the naturally infected birds get a score of 2, moderately infected birds received a score of 4 and severely infected birds receive a score of 6 . The scoring of the clinical signs in the directly challenge bird was half that of the naturally infected birds.

Isolates which were used for challenge were 49 $(\mathrm{A}-1), 58(\mathrm{~B}-1), 7(\mathrm{C}-2)$ and $46(\mathrm{C}-3)$ of the NADdependent isolates and isolate $1343(\mathrm{C}-3)$, which is an NAD-independent variant. All of the isolates used have been previously been isolated and serotyped by the author.

As soon as the first clinical signs of IC were seen, the chickens in the bottom row of cages (the same chickens which receive Virukill in the drinking water) were fogged with a $1 \%$ solution of Virukill such that each chicken received approximately $4 \mathrm{~m} \ell$ of diluted disinfectant.
The egg production in each of the groups was also determined by daily counts of the eggs produced. At the termination of the experiment, bacterial samples were collected from both the left and right sinuses of the chickens for bacterial isolation, using the methods described by Bragg et al. (1993).

\section{RESULTS}

\section{Challenge with NAD-dependent isolates}

The different groups of chickens were challenged with the different serovars of NAD-dependent isolates of $H$. paragallinarum. The results of the scoring of the clinical signs were used to produce a graphic representation of the course of the disease. The disease profiles for treated and untreated birds challenged with the different NAD-dependent serovars of $H$. paragallinarum can be seen in Fig. 1, for serovar A-1, Fig. 2 for serovar B-1, Fig. 3 for serovar C-2 and Fig. 4 for serovar C-3. A summary of the mean disease scores for each of the different experimental groups, as calculated from the disease profiles, can be seen in Table 1. The maximum disease score obtained in each of the experimental groups can also be seen in Table 1. Finally, the duration of the infection, as calculated from Fig. 1-4 as the last day on which clinical signs were seen, is presented in Table 1. Statistical analysis of the disease profiles obtained was performed using a t-test and these results are included in Table 1.

\section{Challenge with NAD-independent serovar C-3 isolate}

The disease profiles for treated and untreated birds challenged with NAD-independent serovar C-3 can be seen in Fig. 5 for vaccinated and unvaccinated birds. A summary of the mean disease scores and statistical analysis can be seen in Table 1, together with the maximum disease score for each of the groups of chickens. Finally, the duration of the infection, as calculated from Fig. 5 as the last day on which clinical signs can be seen, is also presented in Table 1.

\section{Egg production}

Eggs were collected from the cages on a daily basis. The number of eggs from each group were carefully recorded and the total number of eggs produced and the number of eggs per bird per day for the different treatments and challenges can all be seen in Table 2. 

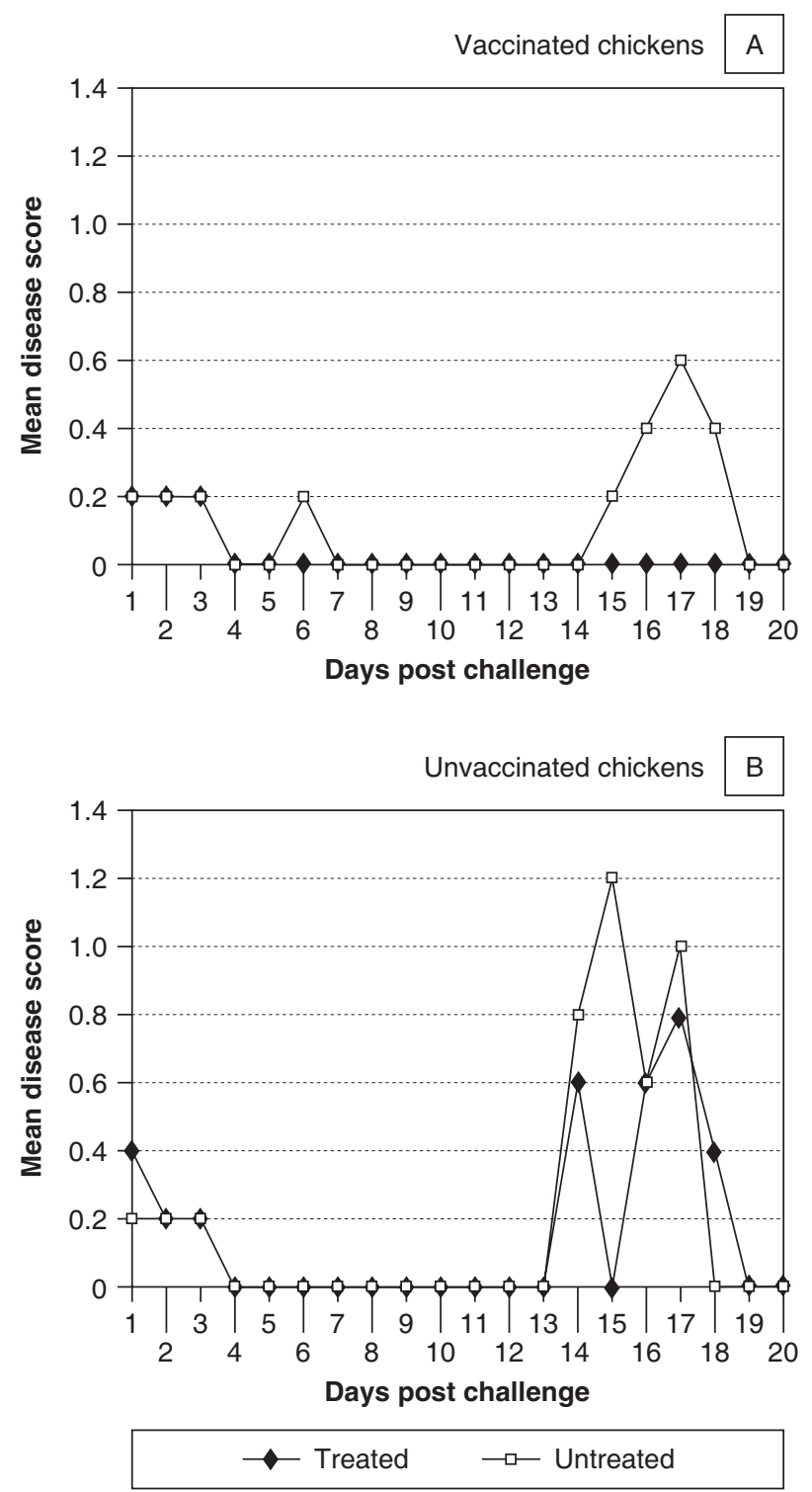

FIG. 1 Disease profiles of vaccinated (A) and unvaccinated (B) chickens challenged with a serovar A-1 isolate of $H$. paragallinarum that were either treated with the continuous disinfection programme (treated) using Virukill or not treated (untreated) in any other way

\section{Bacterial re-isolation}

Twenty days after challenge, all of the surviving chickens were killed and bacterial re-isolations performed on both the left and right sinuses. It was found that there was very little difference between the groups of chickens treated with DDAC and the groups not treated. Approximately $60-70 \%$ of all birds were infected in both the left and right sinuses. There was also no difference between the bacterial re-isolations from the vaccinated and unvaccinated chickens. It must be noted that clinical signs
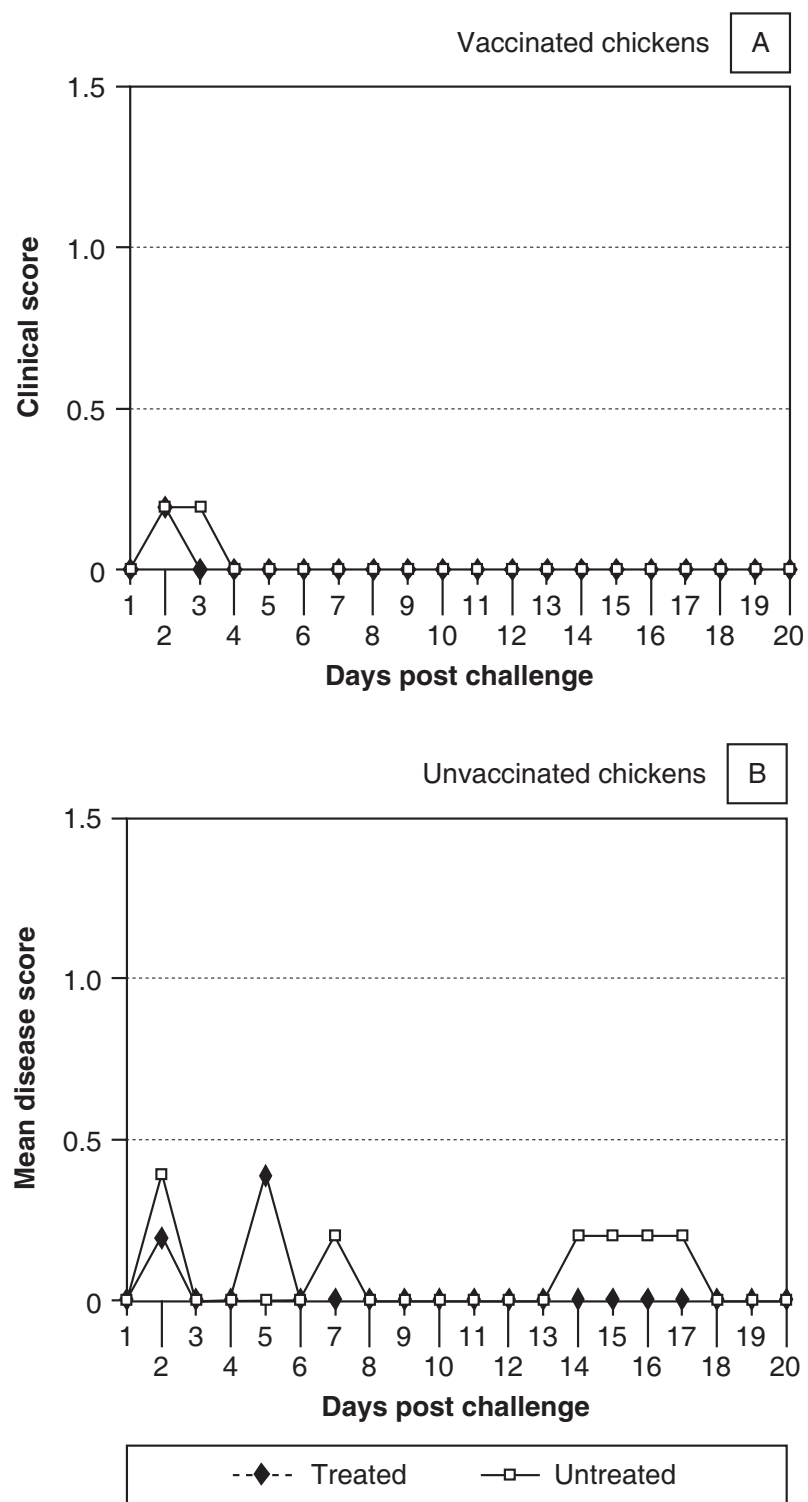

FIG. 2 Disease profiles of vaccinated (A) and unvaccinated (B) chickens challenged with a serovar B-1 isolate of $H$. paragallinarum which were either treated with the continuous disinfection programme using Virukill (treated) or not treated in any other way (untreated)

of IC were noted in all groups of chickens challenged with the different serovars of $H$. paragallinarum in these experiments, irrespective of the vaccination status of the birds or the use of the full continual disinfection programme. For this reason, $\mathrm{H}$. paragallinarum could be re-isolated from each group of birds.

\section{DISCUSSION}

The effects of a full continuous disinfection programme, using DDAC, on the disease profile can 

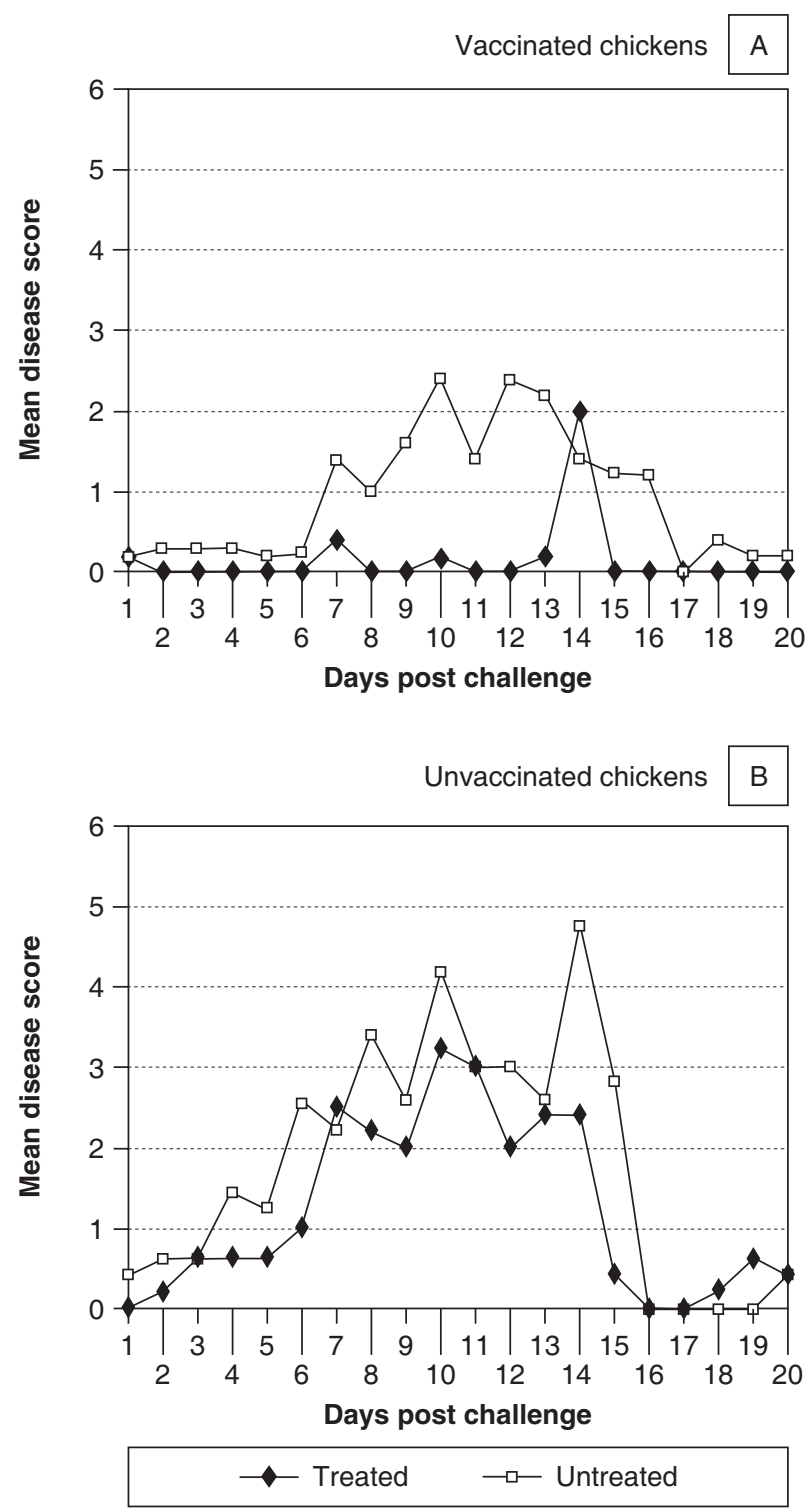

FIG. 3 Disease profiles of vaccinated (A) and unvaccinated (B) chickens challenged with a serovar C-2 isolate of $H$. paragallinarum which were either treated with the continuous disinfection programme using Virukill (treated) or not treated in any other way (untreated)

clearly be seen in Fig. 1-5. The full continuous disinfection program, which consisted of drinking water treatment as well as a daily fogging with DDAC not only reduced the severity of infections, but also, in many cases reduced the duration of infection. In the case of vaccinated chickens challenged with sero$\operatorname{var} A-1$, treatment with DDAC not only reduced the overall clinical signs (which was found to be statistically significant) but also reduced the duration of infection to just 3 days. In the control group, which was housed and infected at the same time as the test group, clinical signs were still recorded up to 20
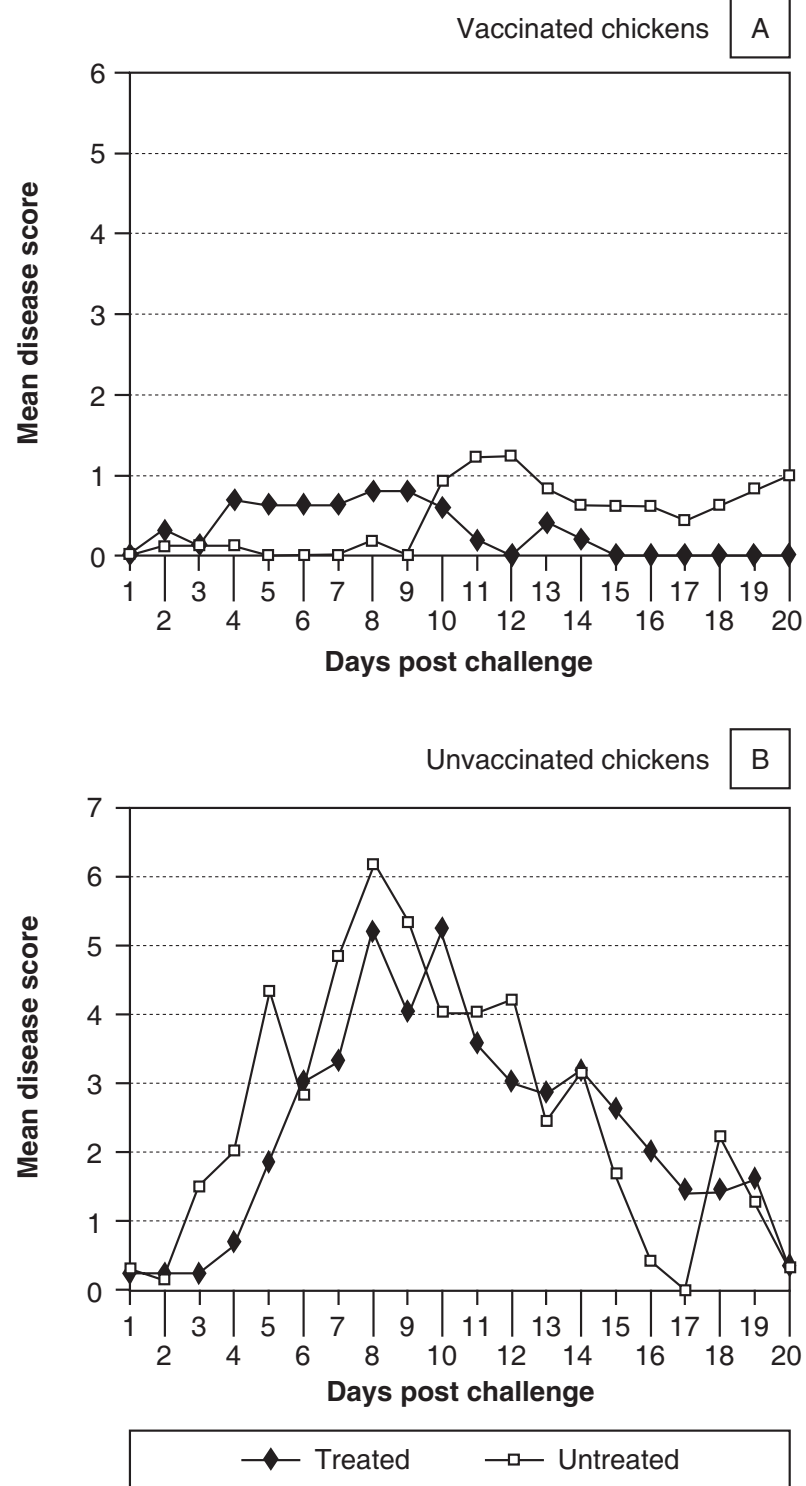

FIG. 4 Disease profiles of vaccinated (A) and unvaccinated (B) chickens challenged with a serovar C-3 isolate of H. paragallinarum which were either treated with the continuous disinfection programme using Virukill (treated) or not treated in any other way (untreated)

days post challenge. Similar reductions in time of clinical signs were seen when the chickens were challenged with the NAD-independent serovar C-3 isolates (Table 1) as well as in unvaccinated birds challenged with serovar B-1). In many of the other experimental challenges, the reduction in the period when clinical signs were seen were not as marked as for the above examples.

It must be stressed at this point that the scale of the $x$-axes of the graphs in Fig. 1-5 are not the same. This is due to the fact that a marked difference in 
Limitation infectious coryza through continuous disinfection programme

TABLE 1 Summary of the disease scores and profiles obtained when vaccinated and unvaccinated chickens challenged with the different serovars of NAD-dependent and NAD-independent isolates of $H$. paragallinarum and either treated with a continuous disinfection program or not treated

\begin{tabular}{|c|c|c|c|c|c|c|}
\hline Isolate & Vaccinated & Treated\# & $\begin{array}{l}\text { Mean disease } \\
\text { score }\end{array}$ & Significance & Highest score & $\begin{array}{l}\text { Duration } \\
\text { (days)\#\# }\end{array}$ \\
\hline A-1 (Dep*) & Yes & Yes & 0.03 & 0.0350 & 0.2 & 3 \\
\hline A-1 (Dep) & Yes & No & 0.12 & & 0.6 & 19 \\
\hline A-1 (Dep) & No & Yes & 0.16 & 0.3128 & 0.8 & 19 \\
\hline A-1 (Dep) & No & No & 0.21 & & 1.2 & 18 \\
\hline B-1 (Dep) & Yes & Yes & 0.01 & 0.2801 & 0.2 & 2 \\
\hline B-1 (Dep) & Yes & No & 0.02 & & 0.2 & 3 \\
\hline B-1 (Dep) & No & Yes & 0.03 & 0.0780 & 0.4 & 5 \\
\hline B-1 (Dep) & No & No & 0.08 & & 0.4 & 17 \\
\hline C-2 (Dep) & Yes & Yes & 0.15 & 0.0009 & 2.0 & 14 \\
\hline C-2 (Dep) & Yes & No & 0.87 & & 2.4 & $>20$ \\
\hline C-2 (Dep) & No & Yes & 1.25 & 0.0648 & 3.2 & $>20$ \\
\hline C-2 (Dep) & No & No & 1.69 & & 4.8 & $>20$ \\
\hline C-3 (Dep) & Yes & Yes & 0.30 & 0.0836 & 0.8 & 14 \\
\hline C-3 (Dep) & Yes & No & 0.43 & & 1.2 & $>20$ \\
\hline C-3 (Dep) & No & Yes & 2.01 & 0.3200 & 5.2 & 19 \\
\hline C-3 (Dep) & No & No & 2.45 & & 6.2 & 19 \\
\hline C-3 (Indep**) & Yes & Yes & 0 & 0.0001 & 0 & 0 \\
\hline C-3 (Indep) & Yes & No & 0.41 & & 1.2 & 15 \\
\hline C-3 (Indep) & No & Yes & 0.04 & 0.0006 & 0.4 & 2 \\
\hline C-3 (Indep) & No & No & 0.41 & & 1.3 & 19 \\
\hline
\end{tabular}

\# Treated with Virukill in the drinking water at 100 ppm daily and fogged with a $1 \%$ Virukill solution daily after observation of the first clinical signs

\#\# Calculated as the last day on which clinical signs were seen in the group of chickens

* NAD dependent

** NAD independent

TABLE 2 Daily egg production and the number of eggs per chicken per day for the experimental period

\begin{tabular}{|l|l|l|l|l|}
\hline Challenged & Vaccinated & Treated\# & Total production & Eggs per bird per day \\
\hline A-1 (Dep) & Yes & Yes & 95 & 0.48 \\
A-1 (Dep) & Yes & No & 83 & 0.42 \\
A-1 (Dep) & No & Yes & 102 & 0.51 \\
A-1 (Dep) & No & No & 67 & 0.34 \\
B-1 (Dep) & Yes & Yes & 125 & 0.63 \\
B-1 (Dep) & Yes & No & 129 & 0.65 \\
B-1 (Dep) & No & Yes & 116 & 0.58 \\
B-1 (Dep) & No & No & 113 & 0.56 \\
C-2 (Dep) & Yes & Yes & 62 & 0.31 \\
C-2 (Dep) & Yes & Yes & 48 & 0.24 \\
C-2 (Dep) & No & No & 107 & 0.54 \\
C-2 (Dep) & No & Yes & 70 & 0.35 \\
C-3 (Dep) & Yes & No & 97 & 0.49 \\
C-3 (Dep) & Yes & Yes & 120 & 0.60 \\
C-3 (Dep) & No & No & 71 & 0.36 \\
C-3 (Dep) & No & Yes & 55 & 0.28 \\
C-3 (Indep** & Yes & No & 152 & 0.76 \\
C-3 (Indep) & Yes & Yes & 125 & 0.63 \\
C-3 (Indep) & No & No & 118 & 0.59 \\
C-3 (Indep) & No & 121 & 0.61 \\
\hline
\end{tabular}

\# Treated with Virukill in the drinking water at $100 \mathrm{ppm}$ daily and fogged with a 1\% Virukill solution daily after observation of the first clinical signs

* NAD dependent

** NAD independent 

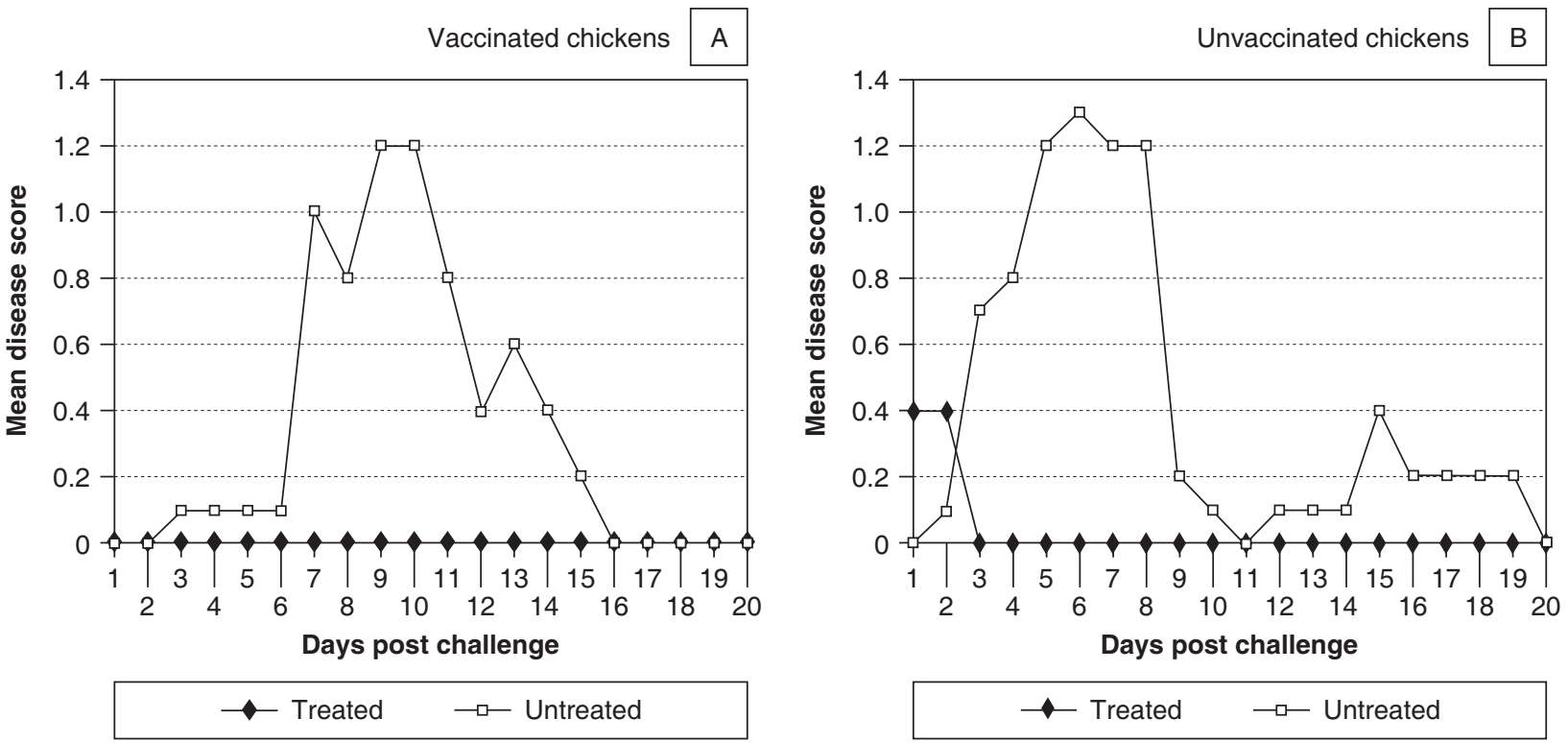

FIG. 5 Disease profiles of vaccinated (A) and unvaccinated (B) chickens challenged with an NAD-independent serovar C-3 isolate of $H$. paragallinarum which were either treated with the continuous disinfection programme using Virukill (treated) or not treated in any other way (untreated)

virulence was detected between the different serovars of the NAD-dependent isolates. It was interesting to note that in this experiment, the serovar C-3 isolate was found to be the most virulent in unvaccinated chickens. This was followed by sero$\operatorname{var}$ C-2. Serovar A-1 showed mild virulence, while serovar B-1 was the least virulent. These results correspond to the findings of Bragg (2002b) where similar virulence patterns were seen. It is also interesting to note that the mean disease scores obtained in these experiments were similar to those obtained by Bragg (2002b) despite the fact that these chickens were not challenged at the same time. This indicates that the mean disease score remains constant for the different serovars over time.

It was also interesting to note that the NAD-independent isolate used in this experiment was much less virulent than the NAD-dependent serovar C-3 isolate. This is in agreement with the findings of Bragg (2002c) who demonstrated that the NADindependent isolates were less virulent than the NAD-dependent isolates of the same serovar.

In Table 2, the effects of the full continuous disinfection program treatment on egg production can be seen. In most cases, the chickens subjected to the full continuous disinfection program laid more eggs than those not receiving the treatment. In some cases there is a substantial difference between the numbers of eggs per chicken per day in the treated group. For example, when unvaccinated chickens were challenged with serovar A-1 (which appears to be of low virulence) the egg production in the treated group was 0.51 eggs per bird per day. In the untreated control group, this was 0.34 eggs bird day. Over the 20 days of the experimental challenge, this difference resulted in 102 eggs being produced by the ten chickens forming the treated group, while the control group produced only 67 eggs. Similar substantial differences in egg production were also seen when unvaccinated chickens were challenged with Serovar C-2. In most other cases improved egg production was recorded. Where no improved egg production was seen as a result of the treatment the chickens showed only very mild clinical signs (for example when the chickens were challenged with serovar B-1). A notable exception to this was when vaccinated chickens were challenged with the NAD-independent serovar C isolate. In this case, higher egg production was recorded in the control group. Statistical analysis was not performed on the egg production data of the different groups as only ten birds per group were used. The egg production in these experiments was recorded as an indication of the effects of the full continuous disinfection on the impact of IC on the birds.

It must be noted that the birds were sprayed with the disinfectant only when the first clinical signs of IC were recorded. The disinfectant was used in the drinking water from when the birds where placed into the cages. This method was selected to simu- 
late what would happen on a production farm, were spraying with a disinfectant would only start once clinical signs were seen. In the full continuous disinfection programme in broilers (Bragg \& Plumstead 2003) birds were routinely sprayed with DDAC from date of placement. If this approach was followed in these experiments, the impact of $H$. paragallinarum on the birds might have been even further reduced.

\section{CONCLUSIONS}

From these results it can be seen that treatment of chickens infected with IC with the non-toxic disinfectant DDAC reduced the duration and severity of clinical signs of the disease. Furthermore, in most cases, treatment with the disinfectant also resulted in higher egg production, in the face of challenge by H. paragallinarum.

It must be stressed that these experiments were done on a small scale in experimental layer cages with only ten chickens per group. Although there is a good indication from these results that treatment with DDAC can reduce the severity of infection, these finds need to be substantiated on full-scale production facilities where detailed statistical analysis could be performed on a larger population.

It is also extremely important to note that the treatment of chickens with DDAC should not be seen as a replacement for effective vaccination. In all of the cases, there was a significant difference between the disease profiles of the vaccinated chickens compared to the unvaccinated ones. In none of the cases examined was the disease profile of the unvaccinated chickens which had been treated with DDAC less then that disease profile of vaccinated untreated chickens. The effective vaccination of chickens remains the main defence against IC.

\section{ACKNOWLEDGEMENTS}

I am grateful to ICA International Chemicals, Stellenbosch, who funded this research.

\section{REFERENCES}

BLACKALL, P.J., EAVES, L.E. \& ROGERS, D.G. 1990. Proposal of a new serovar and altered nomenclature for Haemophilus paragallinarum in the Kume hemaglutinin scheme. Journal of Clinical Microbiology, 28:1185-1187.

BRAGG, R.R. 2002a. Isolation of serovar C-3 Haemophilus paragallinarum from Zimbabwe: A further indication of the need for local vaccines against infectious coryza. Onderstepoort Journal of Veterinary Research , 69:129-132.

BRAGG, R.R. 2002b. Virulence of South African isolates of Haemophilus paragallinarum. Part 1: NAD-dependent field isolates. Onderstepoort Journal of Veterinary Research, 69: 163-169.

BRAGG, R.R. 2002c. Virulence of South African isolates of Haemophilus paragallinarum. Part 2: Naturally occurring NAD-independent field isolates. Onderstepoort Journal of Veterinary Research, 69:171-175.

BRAGG, R.R. \& PLUMSTEAD, P. 2003. Continuous disinfection as a means to control infectious diseases in poultry. Evaluation of a continuous disinfection programme for broilers. Onderstepoort Journal of Veterinary Research, 70:219-229.

BRAGG, R.R., COETZEE, L. \& VERSCHOOR, J.A. 1993. Plasmid encoded NAD independence in some South African isolates of Haemophilus paragallinarum. Onderstepoort Journal of Veterinary Research, 60:147-152.

BRAGG, R.R., COETZEE, L. \& VERSCHOOR, J.A. 1996. Changes in the incidence of the different serovars of Haemophilus paragallinarum in South Africa: A possible explanation for vaccination failures. Onderstepoort Journal of Veterinary Research, 63:217-226.

BRAGG, R.R., GREYLING, J.M. \& VERSCHOOR, J.A. 1997. Isolation and identification of NAD-independent bacteria from chickens with symptoms of infectious coryza. Avian Pathology, 26:595-606.

KUME, K., SAWATA, A., NAKASE, Y. \& MATSUMOTO, M. 1983. Serological classification of Haemophilus paragallinarum with a hemagglutinin scheme. Journal of Clinical Microbiology, 17:985-964.

HORNER, R.F., BISHOP, G.C. \& HAW, C. 1992. An upper respiratory disease of commercial chickens resembling infectious coryza, but caused by a $\mathrm{V}$ factor independent bacterium. Avian Pathology, 21:421-427.

HORNER, R.F., BISHOP, G.C., JARVIS, C.J. \& COETZEE, T.H.T. 1995. NAD (V-factor)-independent and typical Haemophilus paragallinarum infecting commercial chickens: a five year field study. Avian Pathology, 24:453-463.

MOUAHID, M., BISGAARD, M., MORLEY, A.J., MUTTERS, R. \& MANNHEIM, W. 1992. Occurrence of V-factor (NAD)independent strains of Haemophilus paragallinarum. Veterinary Microbiology, 31:363-368. 